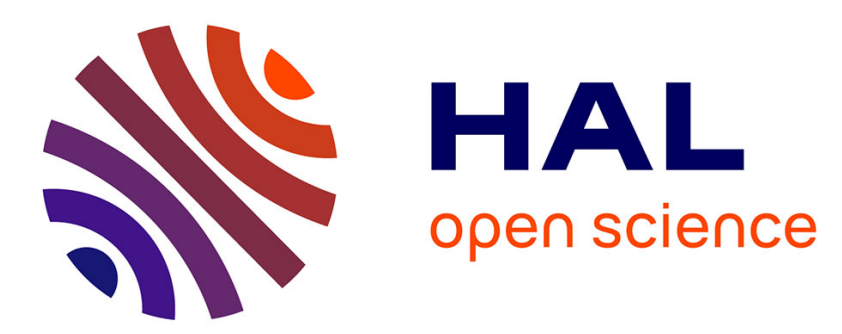

\title{
Adaptation of existing behaviour models to unsaturated states: Application to CJS model
}

Jean-Michel Pereira, Henry Wong, Philippe Dubujet, Patrick Dangla

\section{To cite this version:}

Jean-Michel Pereira, Henry Wong, Philippe Dubujet, Patrick Dangla. Adaptation of existing behaviour models to unsaturated states: Application to CJS model. International Journal for Numerical and Analytical Methods in Geomechanics, 2005, 29 (11), pp.1127-1155. 10.1002/nag.453 . hal-00140210

\section{HAL Id: hal-00140210 https://hal.science/hal-00140210}

Submitted on 5 Apr 2007

HAL is a multi-disciplinary open access archive for the deposit and dissemination of scientific research documents, whether they are published or not. The documents may come from teaching and research institutions in France or abroad, or from public or private research centers.
L'archive ouverte pluridisciplinaire HAL, est destinée au dépôt et à la diffusion de documents scientifiques de niveau recherche, publiés ou non, émanant des établissements d'enseignement et de recherche français ou étrangers, des laboratoires publics ou privés. 


\title{
Adaptation of existing behaviour models to unsaturated states: Application to CJS model
}

\author{
Jean-Michel Pereira ${ }^{1}$, Henry Wong ${ }^{1, *}$, Philippe Dubujet $^{2}$ and Patrick Dangla ${ }^{3}$ \\ ${ }^{1}$ Département Génie Civil et Bâtiment, Laboratoire Géomatériaux, URA CNRS 1652 \\ École Nationale des Travaux Publics de l'État, Vaulx-en-Velin, France \\ 2 Laboratoire de Tribologie et Dynamique des Systèmes, UMR CNRS 5513 \\ École Nationale d'Ingénieurs de Saint-Étienne, Saint-Étienne, France \\ ${ }^{3}$ Laboratoire des Matériaux et des Structures du Génie Civil, UMR CNRS 113 \\ Laboratoire Central des Ponts et Chaussées, Champs-sur-Marne, France
}

\section{SUMMARY}

This paper proposes a general formulation of an elastoplastic model adapted to unsaturated soils. This formulation enters within the framework of two independent state variables descriptions. The choice of a particular effective stress combined with suction is made. The definition of this effective stress is based on the formulation of an equivalent pore pressure which is an essential point of this type of models. It will be discussed in this paper.

This general formulation can be seen as a methodology allowing to adapt in a straightforward way most of elastoplastic behaviour models classically used in saturated soils mechanics to unsaturated states. It is shown that this synthesis can include most of recent models developed within the same framework.

The last part of this paper is devoted to the adaptation of an existing complex elastoplastic model (CJS model) to unsaturated states using the methodology previously exposed. The model thus obtained is validated on various loading paths including odometric, isotropic or triaxial compressions and also wetting tests simulating collapse phenomenon.

This model extension shows the easiness introduced by the proposed methodology to adapt a given elastoplastic model to unsaturated states. Its validation illustrates by the way the abilities of the extended model to reproduce complex volumetric responses of an unsaturated soil. Copyright (c) 2005 John Wiley \& Sons, Ltd.

KEY WORDS: unsaturated soils; effective stress; equivalent pore pressure; constitutive model; elastoplasticity; validation

\section{NOTATIONS AND CONVENTIONS}

Tensorial quantities are denoted in bold and scalar quantities are represented using lightfaced characters. Accordingly to soil mechanics convention, compressive stresses and contractive strains are counted positively.

${ }^{*}$ Correspondence to: Henry Wong, Département Génie Civil et Bâtiment, Laboratoire Géomatériaux, École Nationale des Travaux Publics de l'État, Rue Maurice Audin, 69518 Vaulx-en-Velin CEDEX, France. Phone: +33(0)472047268. Fax: +33(0)472047156. E-mail: henry.wong@entpe.fr

Copyright (c) 2005 John Wiley \& Sons, Ltd. 


\section{INTRODUCTION}

In soil mechanics, constitutive models are generally formulated for materials saturated with water. However, an increasing number of problems encountered by engineers involve unsaturated soils. This tendency is not only due to the appearance of new study areas involving unsaturated materials like for instance in nuclear waste storage but also to the fact that a large part of the soils on the planet surface are partially saturated (with respect to water). In order to improve behaviour prediction of these soils, this aspect of their state has to be taken into account.

Unsaturated soils present a negative pore water pressure (in reference to pore gas pressure) and show a specific behaviour compared to saturated soils. This difference between gas and liquid pressures (respectively $p_{g}$ and $p_{l}$ ) results in a positive suction $s=p_{g}-p_{l}$. If osmotic effects are not taken into account, this quantity is mainly responsible for the specific behaviour of unsaturated soils. Models describing unsaturated materials then need to account for these specific behaviour aspects and particularly suction effects which concern different levels in the global behaviour of the material. A natural procedure consists in adapting existing models to unsaturated states in order to obtain a more realistic description of unsaturated soils behaviour.

Several attempts have been developed to adapt saturated models to unsaturated soils. These attempts are based on different approaches differing upon the choice of the set of suitable variables describing the material behaviour. This choice is a key point in unsaturated soils modelling and this question remains open. Three distinct approaches can be isolated.

In order to include suction effects, unsaturated soils modelling has started with some attempts to redefine the well-known Terzaghi's effective stress $\boldsymbol{\sigma}^{\prime}$ [27]:

$$
\boldsymbol{\sigma}^{\prime}=\boldsymbol{\sigma}-p_{l} \mathbf{1}
$$

where $\sigma$ and 1 are respectively the total stress and identity tensors. The advantages of this approach is that behaviour models can be adapted to unsaturated states in a straight-forward manner: Terzaghi's effective stress is simply replaced by the new effective stress in model's original formulation. The most famous proposal is due to Bishop [3] who defined an effective stress as:

$$
\begin{aligned}
\boldsymbol{\sigma}^{\prime} & =\boldsymbol{\sigma}-(1-\chi) p_{g} \mathbf{1}-\chi p_{l} \mathbf{1} \\
& =\boldsymbol{\sigma}-p_{g} \mathbf{1}+\chi s \mathbf{1}
\end{aligned}
$$

where $\chi$ is a function allowing to weight liquid and gas pressures effects on the effective stress. Bishop and Blight provided experimental evidence suggesting the validity of their effective stress definition with $\chi=S_{l}$ (under the assumption of grains incompressibility).

Predictions of those models using an effective stress as unique independent state variable are correct concerning some aspects like shear strength but are inefficient in describing other particular aspects of unsaturated soils behaviour like the collapse phenomenon which occurs during wetting of soils subjected to high mean stresses.

In order to remedy such deficiencies, later attempts have used more than one independent state variable. Several significant contributions (as for example in [13]) allowed to conclude that any pair among the following three candidates could be selected as relevant independent state variables: $\boldsymbol{\sigma}-p_{l} \mathbf{1}$, $\boldsymbol{\sigma}-p_{g} \mathbf{1}$ and $s$. The last two are generally chosen for the following advantages: firstly, this choice allows to separate the effects of total stress from those of suction. Secondly, the assumption of a continuous gaseous phase with a uniform pressure (equal to the atmospheric pressure datum) is usually accepted in engineering applications [13], thus leading to a further simplification. In [18], the authors 
explained on the contrary the interest to use the "saturated effective stress" $\left(\boldsymbol{\sigma}-p_{l} \mathbf{1}\right)$ rather than the net stress $\left(\boldsymbol{\sigma}-p_{g} \mathbf{1}\right)$ in order to, among others, simplify the transition from partial to total saturation. Some significant works among these attempts can be cited like for example Alonso et al. model [2] or Wheeler et al. contributions [28] [29].

More recently, within the framework of two state variables descriptions, the choice of an "effective stress" accounting for positive suction appeared in the literature. This "effective stress" is referred to as "constitutive stress" by some authors (see [25] for instance). Such approaches combine advantages of an effective stress (continuity of behaviour description at transition between saturated and unsaturated domains) and possibilities offered by models using two independent state variables. The main difficulty inherent in this type of description lies in the formulation of an equivalent pore pressure necessary to define the unsaturated effective stress.

Several recent approaches proposed new definitions for the effective stress. They differ mainly by the definition of the equivalent pore pressure used in the effective stress definition.

This paper proposes a general formulation of an unsaturated elastoplastic model whose purpose is to facilitate the adaptation of existing saturated elastoplastic models to partially saturated states. This formulation will then be confronted to the various quoted models.

Since recent unsaturated formulations are based on simple elastoplastic models, the proposed formulation will finally be the basis of the adaptation to unsaturated states of a more advanced behaviour model in order to demonstrate the abilities and generality of the proposed methodology. The CJS model, originally developed by the research team of École Centrale de Lyon (France), will be used and eventually validated on various loading paths including œdometric, isotropic or triaxial compressions and also wetting tests simulating collapse phenomenon.

\section{DEFINING AN UNSATURATED BEHAVIOUR MODEL}

\subsection{Features to be included in an unsaturated model}

Before the general formulation proposal, it seems convenient to describe the main characteristics of unsaturated soils behaviour that a model should be able to predict.

Concerning the hydric behaviour of unsaturated soils (submitted to suction loadings under constant total stress), the main observations are: (i) during a drying step, the liquid saturation degree $S_{l}$ remains constant equal to unity for suctions below the so-called air entry suction $s_{e}$; (ii) for normally consolidated soils, irreversible deformations appear for suctions below $s_{e}$ while behaviour becomes reversible above ; (iii) hysteresis phenomenon is observed during a drying-wetting cycle ; (iv) a collapse (large void ratio decrease) may be encountered on wetting paths under high mean stresses while swelling is observed at low mean stresses.

Concerning the mechanical behaviour, a suction increase induces a strengthening of the material. This phenomenon can be traduced by a higher elastic limit and a certain inhibition of the plastic strains that the soil could undergo. It has also been observed that a suction increase tends to increase the "internal confinement" via an increase in intergranular contact forces (see [16] and [17] for example). During shear tests at constant suction, the volumetric behaviour is firstly contractant and becomes dilatant afterwards, the dilatancy being more pronounced at higher suctions.

It should be noted that, in the domain of suctions comprised between zero and $s_{e}$, the Terzaghi's effective stress is generally assumed to remain valid. The only difference with "classical" saturated soils is that the liquid pore pressure is negative. In this domain, it could moreover be necessary to 
modify the liquid compressibility in order to account for the possible presence of occluded gaz bubbles.

\subsection{Choice of independent state variables}

An essential feature that should also be present in a model is its ability to cross the transition between saturated and unsaturated conditions. This transition should be simple to incorporate when, for example, a numerical implementation of the model is envisaged.

For this reason, using an effective stress in a model presents undeniable advantages. Only the last approach mentioned before will be considered next: effective stress and suction will be used as independent state variables. It is worthy to highlight that the denomination "effective stress" may be ambiguous. It does not correspond to the definition proposed by Terzaghi (unique independent state variable linking stresses to strains). Indeed the effective stress used here is not sufficient to describe the overall behaviour. As it will be seen later, suction also intervenes explicitly in the yield surface definition which is not the case for saturated models in which liquid pressure intervenes only indirectly via the effective stress. However this denomination is conserved because of its similarities with the standard saturated effective stress (physical intuition, mathematical formulation, etc.)

\subsection{Definition of the equivalent pore pressure}

The formulation of an equivalent pore pressure is of first importance in the elaboration of an unsaturated behaviour model. A discussion concerning its definition is now proposed.

From a theoretical point of view, the equivalent pore pressure used in this paper is defined as the pressure of a fluid saturating the material and inducing the same behaviour as that of the material in partially saturated conditions: it is the pore pressure of a fictitious fluid.

The formulation of this pore pressure is the point where most of recent models differ from one to another. Once the form of this equivalent pore pressure is formulated, its effects on the mechanical behaviour of the material are treated in similar ways in each model.

It should be noted that the "effective stress approach" leads to a unique elastic constitutive relation linking both net stress and suction variations to volume changes via the effective stress. This is in sharp contrast to other approaches using two independent stress variables, which use two separate relations for the same purpose (one relation per stress variable). An "effective stress approach" thus induces some conditions on its own definition which do not appear with other approaches: a unique stressstrain relation has to describe loadings that may concern (independently or not) two stress variables (net stress and suction for instance). Interested reader is reported to [24] for a developed discussion on that subject.

\section{UNSATURATED MODEL GENERAL FORMULATION}

For the sake of simplicity, only isotropic behaviour is considered ; extension to behaviour under deviatoric loadings will be discussed in section 3.4.

\subsection{Assumptions and definitions}

General assumptions and definitions concerning the proposed formulation are now presented.

Following Coussy \& Dangla [7]: (i) an equivalent pore pressure $\pi$ is introduced. It is defined such that, under saturated conditions, it would induce an equivalent behaviour as that of the unsaturated soil 

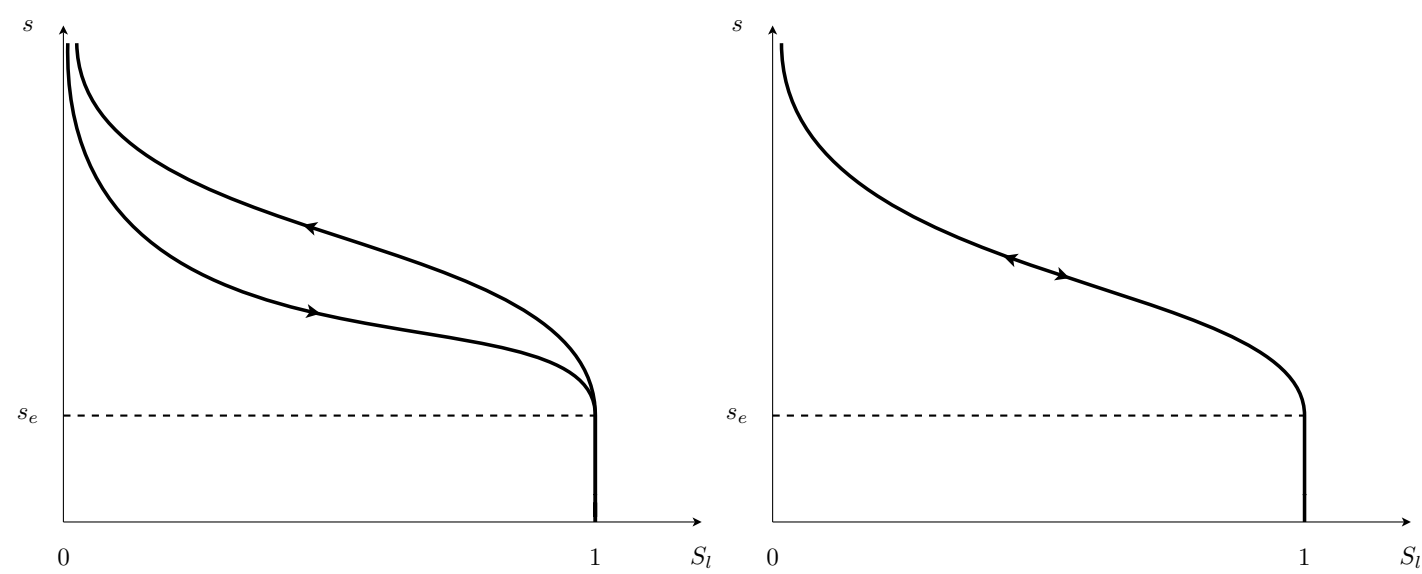

Figure 1. General aspect of a sorption curve: experimental (left) and simplified (right).

at the present state ; (ii) the tensor

$$
\boldsymbol{\sigma}^{\prime}=\boldsymbol{\sigma}+\pi \mathbf{1}
$$

plays the role of an effective stress tensor. Terzaghi's effective stress is supposed to remain valid as far as suction remains below the air entry suction. Note that $\pi(s)$ is positive for positive suctions.

Hereafter it is assumed that the equivalent pore pressure $\pi$ only depends on suction (it could however have been supposed that it depends also on skeleton deformations).

The sorption curve (drying-wetting curve) will be idealized and supposed to be a bijection between suction and saturation degree of the liquid phase. Hysteresis during a drying-wetting cycle is thus neglected (see Figure 1).

A suction increase intervenes in two different ways. Firstly, it intervenes as a loading. This is dealt with by an effective stress increment as a consequence of Eq. (3). Secondly, it increases the binding between the solid grains, hence increasing the stiffness and strength. This second aspect is taken into account by the state-dependent stiffness and by the introduction of a suction hardening (ie yield surface expansion due to suction increase). In other words, yield surface definition is:

$$
f=f\left(\boldsymbol{\sigma}^{\prime}, s, \boldsymbol{X}\right)
$$

where $\boldsymbol{X}$ is a hardening variable which may be either a tensor or a scalar variable depending on the hardening type considered (kinematic or isotropic).

The resulting hardening laws derive from classical elastoplastic modelling formalism and will be discussed hereafter.

\subsection{Generalized isotropic model}

3.2.1. Pore pressure and effective stress The equivalent pressure $\pi$ must be defined such that a suction increase would induce an increase of the effective stress. It must also account for the fact that Terzaghi's effective stress is valid for suctions below air-entry value. The continuity of $\pi$ at the saturation limit 
$\left(s=s_{e}\right)$ is supposed. Hence, we will impose in the sequel:

$$
\begin{aligned}
& \forall s \leq s_{e}, \quad \pi(s)=-p_{g}+s=-p_{l} \\
& \forall s>s_{e}, \quad \frac{\partial \pi}{\partial s}>0 \\
& \pi(s) \text { continuous at } s=s_{e},
\end{aligned}
$$

Several formulations of $\pi(s)$ are given in what follows when comparing this general formulation to various recent models.

According to Eq. (3), the isotropic effective stress $p^{\prime}$ is defined by:

$$
p^{\prime}=p+\pi
$$

where $p$ is the isotropic total stress.

3.2.2. Elastic behaviour An isotropic elastic law can be formulated in an incremental way in the following general form :

$$
d \epsilon_{v}^{e}=\frac{1}{K} d p^{\prime}
$$

where $K$ may depend on the stress/strain state, $d \epsilon_{v}^{e}$ is the volumetric elastic strain increment.

3.2.3. Yield surface For a given suction, the elastic domain in terms of effective stress is limited by a preconsolidation pressure denoted $p_{\pi}^{\prime}$. For a given deformation state, this limit is supposed to be a function of the suction only. Its evolution with respect to suction is subject to some conditions imposed by experimental observations: elastic behaviour for suction increases above the air-entry suction and collapse during wetting at constant high mean stresses.

As discussed previously, the description of these phenomena can only be achieved by incorporating a second independent state variable into the yield function definition. The choice of suction is made here.

As both effective stress and preconsolidation pressure depend on suction, the two cited phenomena can be simulated only if the preconsolidation pressure vary more rapidly than $p_{g}+\pi$ during a suction change. In other words, the yield surface expansion must be faster than the effective stress increase, hence:

$$
\forall s \geq s_{e}, \quad \frac{\partial p_{\pi}^{\prime}}{\partial s}>\frac{\partial\left(p_{g}+\pi\right)}{\partial s}
$$

As far as isotropic behaviour is concerned, the following expressions for the yield surface and preconsolidation pressure are proposed:

$$
\begin{gathered}
f\left(\sigma^{\prime}, s, p_{0}^{\prime}\right) \equiv p^{\prime}-p_{\pi}^{\prime}=0 \\
p_{\pi}^{\prime}=p_{0}^{\prime} l_{1}(s)+l_{2}(s)
\end{gathered}
$$

where $p_{0}^{\prime}$ and $p_{\pi}^{\prime}$ are the mean effective preconsolidation stresses respectively at saturation and at a given suction. The formulation of $p_{\pi}^{\prime}$ given here is inspired from the work of Loret $\&$ Khalili [20]. It enables to include most of the quoted models.

Functions $l_{1}$ and $l_{2}$ allow to account for suction hardening. Choice of these functions is particularly important since it determines the shape of the yield surface in the $\left(p^{\prime}, s\right)$ plane and therefore controls the collapse behaviour. As it will be seen later, function $l_{1}$ induces moreover a coupling between suction and mechanical hardening (Eq. 14) thus affecting the expansion rate of the yield surface. 
In order to satisfy conditions (5) and (8), we will impose that:

$$
\begin{aligned}
& \forall s \leq s_{e}, \quad l_{1}(s)=1 \\
& \forall s>s_{e}, \quad \frac{d l_{1}}{d s}>0 \\
& \forall s \leq s_{e}, \quad l_{2}(s)=0 \\
& \forall s>s_{e}, \quad \frac{d l_{2}}{d s}>0 \\
& \forall s>s_{e}, \quad p_{0}^{\prime} \frac{d l_{1}}{d s}+\frac{d l_{2}}{d s}>\frac{\partial\left(p_{g}+\pi\right)}{\partial s}
\end{aligned}
$$

In consequence, the isotropic elastic boundary remains constant for $0 \leq s \leq s_{e}$, that is:

$$
\forall s \in\left[0, s_{e}\right], \quad p_{\pi}^{\prime}=p_{0}^{\prime}
$$

3.2.4. Flow rule The flow rule gives the plastic strain increment induced by a load increment. Since an effective stress is considered for the model formulation and by analogy with saturated models, the flow rule must necessary be written as, for the isotropic part:

$$
d \epsilon_{v}^{p}=d \lambda \frac{\partial g}{\partial p^{\prime}}
$$

where $d \epsilon_{v}^{p}$ is the volumetric plastic strain increment, $d \lambda$ is the plastic multiplier and $g$ is the plastic potential. $d \lambda$ can be calculated from the consistency condition: $f=0$ and $\dot{f}=0$ by assuming plastic loading. The plastic potential $g$ is identified to the yield function in a standard materials framework.

3.2.5. Hardening law The hardening law gives the evolution of the hardening variable during a plastic loading. It can formally be written in the following way:

$$
d p_{0}^{\prime}=d \lambda \mathcal{H}\left(p_{0}^{\prime}, s\right)
$$

The definition of the function $\mathcal{H}\left(p_{0}^{\prime}, s\right)$ depends on the model from which the adaptation is carried out.

The hardening process is held by the preconsolidation pressure at zero suction $p_{0}^{\prime}$ in order to allow a simple transition between saturated and unsaturated conditions.

The hardening law having been defined, the hardening modulus $H$ can now be calculated. It is defined by the relation:

$$
\frac{\partial f}{\partial p_{0}^{\prime}} d p_{0}^{\prime}=-d \lambda H
$$

Use of yield surface (Eqs. 9) as well as hardening law (13) leads finally to identify the hardening modulus:

$$
H=l_{1}(s) \mathcal{H}\left(p_{0}^{\prime}, s\right)
$$

This relation shows the particular role played by the $l_{1}$ function which in addition to influencing the shape of the yield surface in the $\left(p^{\prime}, s\right)$ plane (as does $l_{2}$ ) also allows a coupling between suction effects and mechanical hardening thus affecting the expansion rate of the yield surface. Indeed, it can easily be shown that the plastic multiplier $d \lambda$ depends on the hardening modulus so that, according to (Eq. 13), $p_{0}^{\prime}$ variations depend on $H$ and thus on $l_{1}(s)$. 


\subsection{Comparison with various recent approaches}

The general formulation is now confronted to a few models recently proposed, which use effective stress and suction as independent state variables. These models have been chosen because they follow different approaches and because they represent significant contributions in their respective approach.

3.3.1. Kohgo et al. model In [16] and [17], the authors proposed an equivalent pore pressure whose definition is based on an empirical study of shear strength $v s$ suction. They also provided a theoretical framework based on a micromechanical approach, giving a physical meaning to both equivalent pore pressure and effective stress, thereby relating intergranular contact forces to suction. This connection gives an intuitive appreciation of what effective stress is.

Their equivalent pore pressure is such that it starts at $\pi\left(s_{e}\right)=s_{e}-p_{g}$ and tends asymptotically at high suctions to a value that they call the "critical suction" $s_{c}$.

The equivalent pore pressure is defined by:

$$
\pi(s)= \begin{cases}-p_{g}+s & \text { for } s \leq s_{e} \\ -p_{g}+\left(s_{e}+\frac{s_{c}-s_{e}}{s^{*}+a_{e}} s^{*}\right) & \text { for } s>s_{e}\end{cases}
$$

where $s^{*}=s-s_{e}$ is an effective suction. $s_{c}$ and $a_{e}$ are parameters and $s_{c}$ defines the asymptotic limit of $\pi$.

The Modified Cam Clay model is used as the plastic driver. Concerning the yield surface and the hardening law, the authors directly gave $p_{\pi}^{\prime}$ as a function of suction and the total volumetric plastic strain. This formulation cannot be easily incorporated in the generalization proposed here. It can however be compared to the formulation given in the Barcelona model (see [2]). This last point will be discussed again in section 3.3.4.

3.3.2. Abou-Bekr model In [1], the author started from a simplified micromechanical model on an idealized soil (uniform-sized spherical grains stacking) in order to define analytically an equivalent pore pressure function, similarly to the approach followed by Kohgo et al. Inspired by the form of this analytical function, he then went on to postulate an empirical equivalent pore pressure function, applicable to real soils.

Like in Kohgo et al., a maximum pore pressure $\pi_{\max }$ is assumed to be reached for high suctions. According to Abou-Bekr, this maximum equivalent pore pressure is a function of surface tension at the liquid-gas interface, of porosity and grain size distribution of the soil. The definition of $\pi_{\max }$ is however based on assumptions linked to the considered microstructure. In practice, it is more adequate to consider $\pi_{\max }$ as a material parameter which will have to be identified with experiments.

Abou-Bekr proposes an equivalent pore pressure formulation which is continuously differentiable in the whole positive suction domain, contrary to the other models:

$$
\forall s \geq 0, \quad \pi(s)=-p_{g}+\pi_{\max } \tanh \left(\frac{s}{\pi_{\max }}\right)
$$

The author adapted Hujeux's model which is quite similar to the Modified Cam Clay model as far as only isotropic stress paths are considered.

Abou-Bekr's preconsolidation pressure $p_{\pi}^{\prime}$ corresponds to taking the following expressions for $l_{1}$ 
and $l_{2}$ :

$$
\begin{gathered}
l_{1}(s)=1 \\
l_{2}(s)=k \pi
\end{gathered}
$$

It can be seen that $l_{2}\left(s_{e}\right) \neq 0$. However, the author implicitly assumes that $l_{1}(s)=1$ and $l_{2}(s)=0$ for all $s<s_{e}$ because of the experimentally observed validity of Terzaghi's effective stress in this domain. Hence the yield function will be discontinuous at the transition between saturated and unsaturated conditions.

The following hardening law is used by Abou-Bekr:

$$
\mathcal{H}\left(p_{0}^{\prime}\right)=K_{0}^{p}\left(\frac{p_{0}^{\prime}}{p_{\text {ref }}}\right)^{n}
$$

3.3.3. Loret \& Khalili model In [20] and [21], the authors based their work on the formulation of Bishop's effective stress (Eq. 2). According to them, $\chi$ can be considered as a scale factor allowing to integrate suction effects at the microscopic scale (at the level of pores) to the macroscopic behaviour (at the scale of the representative elementary volume). They also indicate that it is not correct to identify the function $\chi(s)$ with the degree of liquid saturation $S_{l}(s)$. They propose an empirical formulation for $\chi$ based on a study of shear strength of partially saturated soils and described in [15].

Loret \& Khalili mentioned two reasons to distinguish $\chi(s)$ from $S_{l}(s)$. On one hand, identifying $\chi$ with $S_{l}$ would be incompatible with the use of liquid volume as an independent state variable, since a change of $S_{l}$ would then affect simultaneously the effective stress and the liquid volume, whereas they are already interdependent via the constitutive relation. On the other hand, at high suctions where the degree of liquid saturation is roughly constant, the assumption $\chi=S_{l}$ would lead to proportionality between shear strength and suction which is not observed in experiments.

Their model is based on the mixtures theory applied to triphasic porous media. The complementary use of the sorption curve of the soil (obtained during a drying-wetting cycle test under constant total stress) allows the formulation of evolution laws for liquid and gas volume fractions with respect to stress state variables. These volumetric variables are generally omitted in discussions about constitutive behaviour of unsaturated soils but are in fact necessary when dealing with general loading paths such as undrained tests or in boundary-value problems where variations of $s$ and $S_{l}$ are coupled with mass and momentum conservation.

Loret \& Khalili illustrated their work by adapting the Modified Cam Clay model. The equivalent pore pressure used is given by:

$$
\begin{gathered}
\forall s \geq 0, \quad \pi(s)=-p_{g}+s \chi \\
\chi(s)=\left\{\begin{array}{cc}
1 & \text { for } s \leq s_{e} \\
\left(\frac{s_{e}}{s}\right)^{\gamma} & \text { for } s>s_{e}
\end{array}\right.
\end{gathered}
$$

with $\gamma=0.55$ being a material constant.

In their model, functions $l_{1}$ and $l_{2}$ take the following form:

$$
\begin{gathered}
l_{1}(s)=1+\frac{k_{1}}{s_{e}}\left(s \chi-s_{e}\right) \\
l_{2}(s)=k_{2}\left(s \chi-s_{e}\right)
\end{gathered}
$$

The hardening law used is:

$$
\mathcal{H}\left(p_{0}^{\prime}\right)=\xi p_{0}^{\prime}
$$

where $\xi$ is a material parameter. 


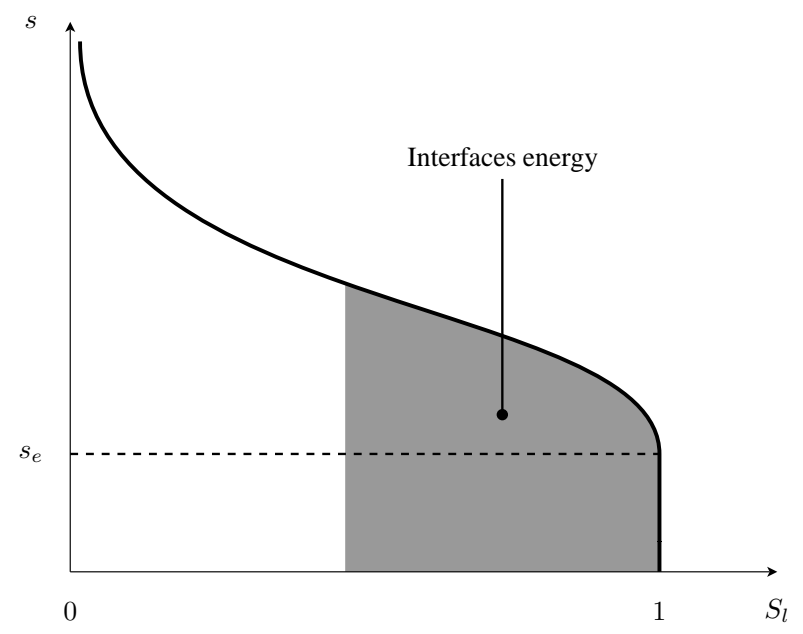

Figure 2. Capillary pressure curve and energy of interfaces.

3.3.4. Dangla \& Coussy model In [7], a thermodynamic approach was developed based on the theory of porous continua (see [6]). The use of this formalism allows to obtain in fine a formulation of the equivalent pore pressure, hence an effective stress definition within the formal framework of the two state variables approach. The developments took into account the energy of the interfaces between the three phases present in the medium.

The authors underlined that such a result consolidates the idea that an effective stress can be used to model unsaturated porous media insofar as the underlying assumptions for its construction are the same as those which justified the pertinence of the effective stress for saturated soils.

In [11], the author used these results to adapt Modified Cam Clay model to unsaturated states. The identification of the equivalent pore pressure requires the knowledge of the capillary pressure curve. The author began with a simple case where hysteresis is absent and the dependence of $S_{l}$ on $s$ is bijective. Moreover, the skeleton strain does not intervene in this relation.

Unlike Loret \& Khalili, no additional information is required other than the function $s \leftrightarrow S_{l}$ to describe the reversible evolution of liquid volume fraction. From this viewpoint, Dangla's model appears to be more fundamental than that of Loret \& Khalili.

In [11], the author adapted the Modified Cam Clay model. After an energetic approach in which energy of phase interfaces was accounted for and introduced by means of an energy denoted $U$, an equivalent pore pressure (counted positively in this paper) is introduced and given in the unsaturated domain by:

$$
\pi(s)=-p_{g}+s S_{l}+\frac{2}{3} U
$$

This energy $U$ represents interfaces energy variations in reference to the saturated state and is supposed to be a function of deformations of the skeleton and of the liquid saturation degree : $U=U\left(\phi, S_{l}\right)$ where $\phi$ is the lagrangian porosity. Interfaces energy variation is illustrated in Figure 2. Once the capillary pressure curve is determined, $U$ can be calculated as:

$$
U\left(\phi, S_{l}\right)=\int_{S_{l}}^{1} s(\phi, S) d S
$$


and the equivalent pore pressure is then given by:

$$
\pi(s)= \begin{cases}-p_{g}+s & \text { for } s \leq s_{e} \\ -p_{g}+s S_{l}+\frac{2}{3} \int_{S_{l}}^{1} s(S) d S & \text { for } s>s_{e}\end{cases}
$$

The term $2 / 3$ multiplying the energy $U$ derives from the assumption concerning the dependence of $U$ upon skeleton deformations. It intervenes in $\pi(s)$ even if the skeleton deformations effects are not accounted for in the interpretation of the capillary pressure curve (see [10] for more details).

The adapted model corresponds to the following particular choice of $l_{1}$ and $l_{2}$ :

$$
\begin{gathered}
l_{1}(s)=l(s) \\
l_{2}(s)=0
\end{gathered}
$$

The author proposes to use a relation of the form (27a) but recognizes that this needs an experimental identification of the function $l(s)$. Because of the lack of such data, the yield surface is calculated using the LC (Loading Collapse) curve of the Barcelona model as a reference. Thus $p_{\pi}^{\prime}$ is evaluated according to the following identification:

$$
p_{\pi}^{\prime}+\pi=p_{g}+p_{0}
$$

where

$$
\frac{p_{0}}{p^{c}}=\left(\frac{p_{0}^{*}}{p^{c}}\right)^{\frac{\lambda(0)-\kappa}{\lambda(s)-\kappa}}
$$

In (29), $p_{0}$ and $p_{0}{ }^{*}$ are net preconsolidation stresses for, respectively, a given suction $s$ and at saturation and

$$
\lambda(s)=\lambda(0)[(1-r) \exp (-\beta s)+r]
$$

$\beta, r, \lambda(0)$ and $\kappa$ are material constants and $p^{c}$ is introduced as a critical pressure.

Interested reader should find more details on the Barcelona model in [2]: this model has not been described in detail in this work because, as a classical reference in unsaturated soils modelling, it is assumed to be well-known to all.

The hardening law used by Dangla is such that:

$$
\mathcal{H}\left(p_{0}^{\prime}\right)=\frac{1+e_{0}}{\lambda(0)-\kappa} p_{0}^{\prime}
$$

where $e_{0}$ is the initial void ratio and $\lambda(0), \kappa$ are the material constants previously mentioned.

3.3.5. General remarks Figure 3 compares formulations of the equivalent pore pressure $\pi$ proposed by the various models. Both approaches by Dangla and Loret \& Khalili differ from the two others in the fact that their equivalent pore pressure do not admit an asymptotic limit.

In the transition to the saturated domain, the various relations verify the limit relation $\pi=-p_{l}$. However, in the case of Abou-Bekr's definition of $\pi$, this verification is only approximate insofar as the pore pressure is not piecewisely-defined, contrary to the others. The relation $\pi+p_{g}=s_{e}$ when $s=s_{e}$ can therefore only be verified in an approximate way by adjusting the $\pi_{\max }$ parameter.

The hardening functions proposed by Loret \& Khalili and by Dangla are equivalent to that used in the Barcelona model (Eq. 32), the first one being initially given in an integral form. It suffises to impose 


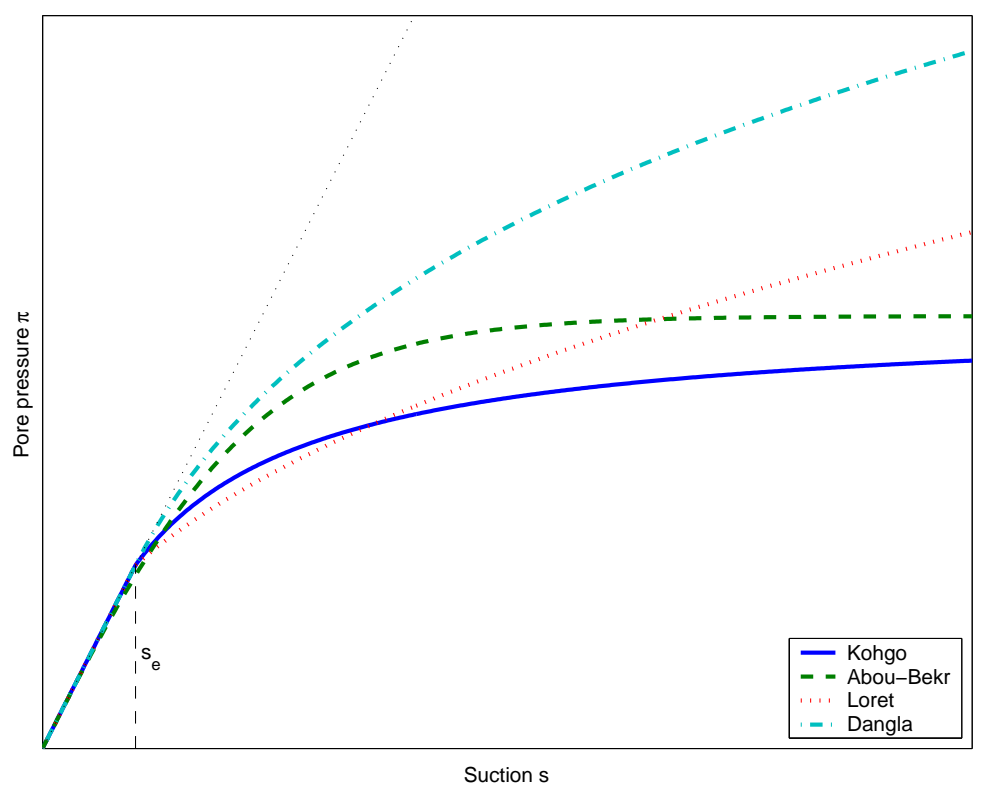

Figure 3. Evolution of the equivalent pore pressure $\pi$ with respect to suction: comparison of various models.

the condition $\xi=\frac{1+e_{0}}{\lambda(0)-\kappa}$ to effectively ensure this equivalence. The hardening function used in the Barcelona model is recalled here for convenience:

$$
\frac{d p_{0}{ }^{*}}{p_{0}{ }^{*}}=\frac{1+e}{\lambda(0)-\kappa} d \epsilon_{v}^{p}
$$

Figure 4 compares the evolutions of the various preconsolidation pressures $p_{\pi}^{\prime}$ with respect to suction (under $p_{g}=0$ assumption). A particularity is attached to Abou-Bekr's model for which the elastic domain is not continuous at the transition between saturated to unsaturated conditions as mentioned in section 3.3.2.

The effective stress measure (2) proposed by Bishop is the one chosen by Loret $\&$ Khalili who proposed a particular form of $\chi$ function. This measure is often used in recent works with $\chi=S_{l}$ (see for instance [4], [19], [25], [26] or [30]). This last choice for $\chi$ appears to be consistent with thermodynamical considerations [14]. It should however be noted that interfaces energy does not appear in such formulations contrary to the formulation proposed by Coussy and Dangla.

\subsection{Extension to a 3D-model}

Extension of this isotropic model to a three dimensional model is quite straightforward but depends on the basis model which has to be adapted to unsaturated states.

In this section, an example with Modified Cam Clay model is presented to illustrate the proposed methodology when applied to models formulated in triaxial stresses space. Extension to real 3D-conditions is identical except that triaxial variables must be replaced by their 3D invariants counterparts.

Extension to unsaturated states of Modified Cam Clay model is submitted to three assumptions 


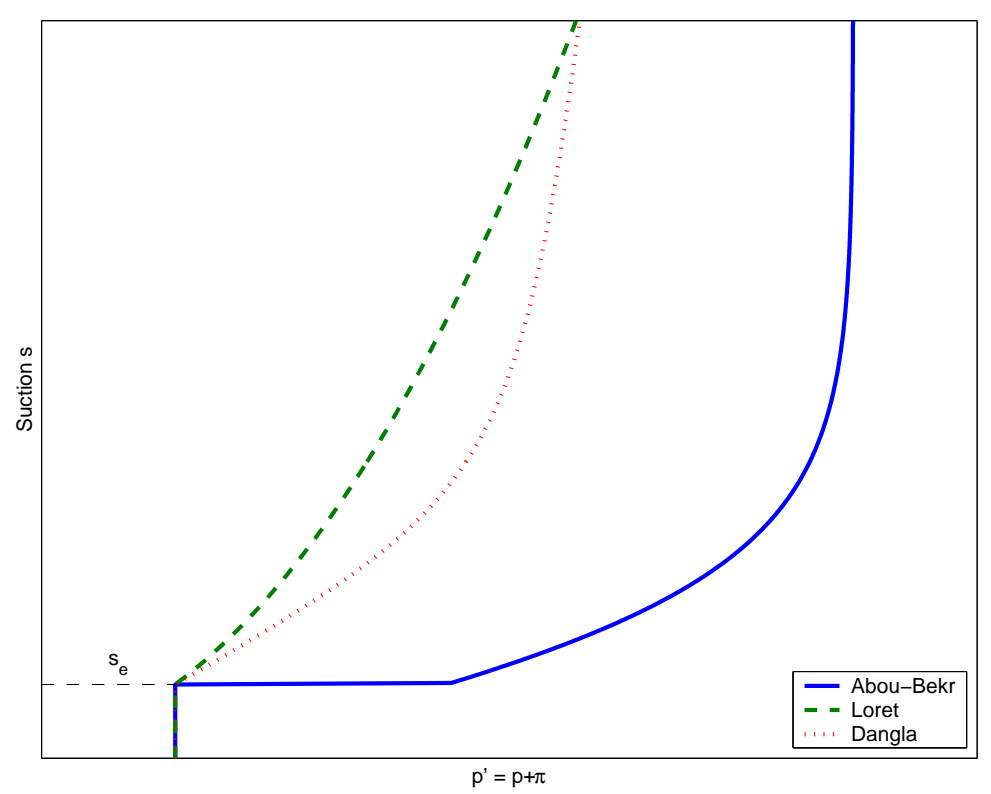

Figure 4. Evolution of the isotropic elastic boundary $p_{\pi}^{\prime}$ with respect to suction: comparison of various models.

(see formulations based on Modified Cam Clay like for instance [11] or [21]) : (i) the shape of the yield surface in $\left(p^{\prime}, q\right)$ (i.e. constant suction) planes is elliptical ; (ii) the critical state line $q=M p^{\prime}$ whose slope $M$ does not depend on suction, intersects the yield surface at its symmetry point ; (iii) the extension limit in terms of effective stress is null for all suctions.

The yield surface is then defined by:

$$
f\left(\boldsymbol{\sigma}^{\prime}, s, p_{0}^{\prime}\right) \equiv q^{2}-M p^{\prime}\left(p_{\pi}^{\prime}-p^{\prime}\right)=0
$$

where $q=\sigma_{1}^{\prime}-\sigma_{3}^{\prime}$ is the triaxial deviatoric stress, $M$ a material constant and $p_{\pi}^{\prime}$ is defined by Eq. (9b).

The flow rule must also be extended to three dimensional stress states (it is expressed here with complete tensors but can easily be converted in terms of triaxial variables):

$$
d \boldsymbol{\epsilon}^{p}=d \lambda \frac{\partial g}{\partial \boldsymbol{\sigma}^{\prime}}=d \lambda\left[\frac{\partial g}{\partial p} \frac{\mathbf{1}}{3}+\frac{\partial g}{\partial q} \frac{3 \boldsymbol{s}}{2 q}\right]
$$

where $\epsilon^{p}$ is the plastic strain tensor and $s=\sigma^{\prime}-\operatorname{tr}\left(\sigma^{\prime}\right) / 31$ is the stress deviator tensor. The plastic potential $g$ can be kept equal to $f$ for the sake of simplicity.

The hardening variable is conserved in this extension so that the hardening law (13) remains unchanged with

$$
\mathcal{H}\left(p_{0}^{\prime}\right)=\frac{1+e_{0}}{\lambda(0)-\kappa} p_{0}^{\prime}
$$

A general form of the elastic law can be defined as:

$$
d \boldsymbol{\epsilon}^{e}=\boldsymbol{C} d \boldsymbol{\sigma}^{\prime}
$$

where $d \epsilon^{e}$ is the elastic strain tensor and $C$ is the elastic stiffness tensor at constant suction (possibly depending on stress/strain state). 
It should be noted that this extension is made easier for the reason that the shape (elliptical) of the yield surface in constant suction planes is assumed. Once the isotropic model is completely defined (particularly the $p_{\pi}^{\prime}(s)$ function), the yield surface formulation is directly obtained. This is all the more true as assumptions on dependency (or not) of $M$ on suction or on limitations of the elastic domain for extension loadings are made. It will be seen in next section that this is not the case with models containing different yield surfaces for isotropic and deviatoric loading paths.

\section{ADAPTATION OF CJS MODEL TO UNSATURATED SOILS}

Most of recent studies on unsaturated soils behaviour modelling use simple models (for instance Modified Cam Clay) as a basis. In the previous section, a synthesis of various recent models has lead to a general formulation allowing to include suction effects into a model developed for dry or saturated soils. In this section, this formulation is used to adapt an advanced model. An interest (among others) to adapt such a model is to benefit from its abilities to describe more accurately the volumetric behaviour of soils under complex loading paths.

\subsection{Original CJS model}

Before adapting it to unsaturated soils, the CJS model as used in this paper is briefly described. The purpose of this paper is not to expose in a extensive way this model; interested reader should find more information in [5], [12] and [22].

The CJS (Cambou-Jaffari-Sidoroff) model was originally developed for saturated granular materials (sands and silts). Its formulation includes three strain mechanisms: one non linear elastic and two plastic mechanisms. These two plastic mechanisms concern respectively isotropic and deviatoric loadings and are submitted to strain-hardening (isotropic in the case of the isotropic mechanism and both isotropic and kinematic in the case of the deviatoric mechanism). For simplicity, the model version considered here is a simplified one in the sense that isotropic hardening associated to the deviatoric plastic mechanism is disabled. However, this version is sufficient to illustrate the proposed adaptation methodology.

4.1.1. Elastic mechanism The elastic mechanism is nonlinear. Elastic strains are incrementally defined by the hypoelastic-type relation:

$$
d \boldsymbol{\epsilon}^{e}=\frac{d I_{1}^{\prime}}{9 K^{e}} \mathbf{1}+\frac{1}{2 G^{e}} d \boldsymbol{s}
$$

where $I_{1}^{\prime}$ is the first invariant of stress tensor and $s$ is the stress deviator tensor, $K^{e}=K_{0}^{e}\left[I_{1}^{\prime} /\left(3 p_{a}\right)\right]^{n}$ and $G^{e}=3 K^{e}(1-2 \nu) /[2(1+\nu)]$ is deduced from Poisson coefficient $\nu$.

Parameters associated to the elastic mechanism are: $K_{0}^{e}, \nu$ and $n . p_{a}$ is the atmospheric pressure and is taken as a reference datum.

4.1.2. Isotropic plastic mechanism The isotropic yield surface is defined by the relation:

$$
f_{I}\left(\boldsymbol{\sigma}^{\prime}, Q\right) \equiv \frac{I_{1}^{\prime}}{3}-Q=0
$$

where $Q$ is the maximum mean effective stress to which the material has been submitted during its history. $Q$ plays the role of the hardening parameter (see Eq. (41)). This yield surface represents a plane orthogonal to $\left(O I_{1}^{\prime}\right)$ axis in the effective stress space (see Figure 5). 
An associated model is considered so that the isotropic plastic potential associated to the isotropic mechanism is identical to the yield surface:

$$
g_{I}=f_{I}
$$

so that the strain increment associated to the isotropic plastic mechanism is classically defined by:

$$
d \epsilon_{I}^{p}=d \lambda_{I} \frac{\partial f_{I}}{\partial \boldsymbol{\sigma}^{\prime}}
$$

where $d \lambda_{I}$ is the plastic multiplier associated to the isotropic plastic mechanism.

The hardening law associated with the isotropic mechanism is isotropic and defined by the relation:

$$
d Q=-K_{0}^{p}\left(\frac{Q}{p_{a}}\right)^{n} d \lambda_{I} \frac{\partial f_{I}}{\partial Q}
$$

Parameters associated to isotropic mechanism are: $K_{0}^{p}$ and $n$.

4.1.3. Deviatoric plastic mechanism The deviatoric yield surface is defined by the relation:

$$
f_{D}\left(\boldsymbol{\sigma}^{\prime}, \boldsymbol{X}\right) \equiv q_{I I} h\left(\theta_{\boldsymbol{q}}\right)-R_{e} I_{1}^{\prime}=0
$$

where

$$
\boldsymbol{q}=\boldsymbol{s}-I_{1} \boldsymbol{X}
$$

$\theta_{\boldsymbol{q}}$ is Lode's angle of $\boldsymbol{q}$ tensor, $q_{I I}$ is the second invariant of $\boldsymbol{q}$ tensor and

$$
h\left(\theta_{\boldsymbol{q}}\right)=\left(1-\gamma \cos \left(3 \theta_{\boldsymbol{q}}\right)\right)^{\frac{1}{m}}
$$

with $m=6$.

$R_{e}$ represents the mean solid angle of the cone formed by the deviatoric yield surface in the stress space and $\boldsymbol{X}$ represents the deviation of the cone axis from $\left(O I_{1}^{\prime}\right)$ axis (see Figure 5) and plays the role of the kinematic hardening parameter (see Eq. (51)).

In this version of CJS model, $R_{e}$ remains constant whereas in the complete elastoplastic model, it is a hardening variable thus introducing isotropic hardening associated to the deviatoric plastic mechanism.

A plastic potential is introduced in order to obtain a better description of the volumetric strains by means of the characteristic state concept (allowing dilatant or contractant behaviour upon the stress state).

This deviatoric plastic potential is not explicitly defined but implicitly via a kinematic condition introducing a coupling between isotropic $\left(d \epsilon_{D v}^{p}\right)$ and deviatoric $\left(e_{D}^{p}\right)$ parts of the plastic strain tensor associated to the deviatoric plastic mechanism:

$$
d \epsilon_{D v}^{p}=\beta\left(\frac{s_{I I} h\left(\theta_{\boldsymbol{s}}\right)}{R_{c} I_{1}^{\prime}}-1\right) \frac{\left|s: d \boldsymbol{e}^{D p}\right|}{s_{I I}}
$$

This results in a plastic potential defined by its gradient:

$$
\frac{\partial g_{D}}{\partial \boldsymbol{\sigma}^{\prime}}=\frac{\partial f_{D}}{\partial \boldsymbol{\sigma}^{\prime}}-\left[\frac{f_{D}}{\partial \boldsymbol{\sigma}^{\prime}}: \boldsymbol{n}\right] \boldsymbol{n}
$$

with

$$
\boldsymbol{n}=\frac{\beta^{\prime} \frac{s}{s_{I I}}-\mathbf{1}}{\sqrt{\beta^{\prime 2}+3}}
$$




$$
\begin{gathered}
\beta^{\prime}=\beta\left[\frac{s_{I I}}{s_{I I c}}-1\right] \operatorname{sign}\left(\boldsymbol{s}: d \boldsymbol{e}_{D}^{p}\right) \\
s_{I I c}=R_{c} \frac{I_{1}^{\prime}}{h\left(\theta_{\boldsymbol{s}}\right)}
\end{gathered}
$$

where $e_{D}^{p}$ is the plastic strain deviator associated to the deviatoric plastic mechanism and $\theta_{\boldsymbol{s}}$ is Lode's angle of stress deviator $s$.

The strain increment associated to the deviatoric plastic mechanism is then classically defined by:

$$
d \boldsymbol{\epsilon}_{D}^{p}=d \lambda_{D} \frac{\partial g_{D}}{\partial \boldsymbol{\sigma}^{\prime}}
$$

where $d \lambda_{D}$ is the plastic multiplier associated to the deviatoric plastic mechanism.

Only the kinematic hardening is conserved in this version of the CJS model. It is defined by the following relation giving the variations of $\boldsymbol{X}$ :

$$
d \boldsymbol{X}=d \lambda_{D} a I_{1}^{\prime}\left[\boldsymbol{Q}-\phi_{0} Q_{I I} h\left(\theta_{\boldsymbol{q}}\right) \boldsymbol{X}\right]\left(\frac{I_{1}^{\prime}}{3 p_{a}}\right)^{-3 / 2}
$$

where $\boldsymbol{Q}$ is defined as the deviatoric part $(\operatorname{dev}()$.$) of \frac{\partial f_{D}}{\partial \boldsymbol{q}}$ so that:

$$
\boldsymbol{Q}=\frac{1}{h^{m-1}\left(\theta_{\boldsymbol{q}}\right)}\left[\left(1+\gamma \frac{3-m}{m} \cos \left(3 \theta_{\boldsymbol{q}}\right)\right) \frac{\boldsymbol{q}}{q_{I I}}-\frac{\gamma}{m} q_{I I} \cos \left(3 \theta_{\boldsymbol{q}}\right) \operatorname{dev}\left(\boldsymbol{q}^{-1}\right)\right]
$$

Parameters associated to the deviatoric plastic mechanism are: $\gamma, \beta, R_{c}, R_{e}, a$ and $\phi_{0}$.

This version of CJS model thus counts 10 parameters.

Figure 5 represents the deviatoric yield surface in 3-dimensional effective stresses space. The surface denoted $f^{R}$ corresponds to the rupture surface: it delimits the admissible stress states and allows to account for rupture states that may occur under certain stress paths. Actually, this surface is implicitly implemented in CJS model via the laws controlling evolution of the hardening variables ( $\boldsymbol{X}$ only in the version used here) which tends asymptotically to a limit value.

\subsection{Adaptation to unsaturated soils}

4.2.1. State variables As previously mentioned, the two state variables are respectively a particular effective stress and suction. The equivalent pore pressure needed for the effective stress definition is based on the work of Dangla \& Coussy [11]:

$$
\pi(s)= \begin{cases}-p_{g}+s & \text { for } s \leq s_{e} \\ -p_{g}+s S_{l}+\frac{2}{3} \int_{S_{l}}^{1} s(S) d S & \text { for } s>s_{e}\end{cases}
$$

As a first approximation, the relation between suction and degree of saturation is supposed to be bijective. The empirical formula proposed by Brooks and Corey (used by Dangla in [11]) will be needed:

$$
S_{l}=\left(\frac{s_{e}}{s}\right)^{\frac{1}{\alpha}}
$$

where $\alpha \geq 1$ is a material parameter. 


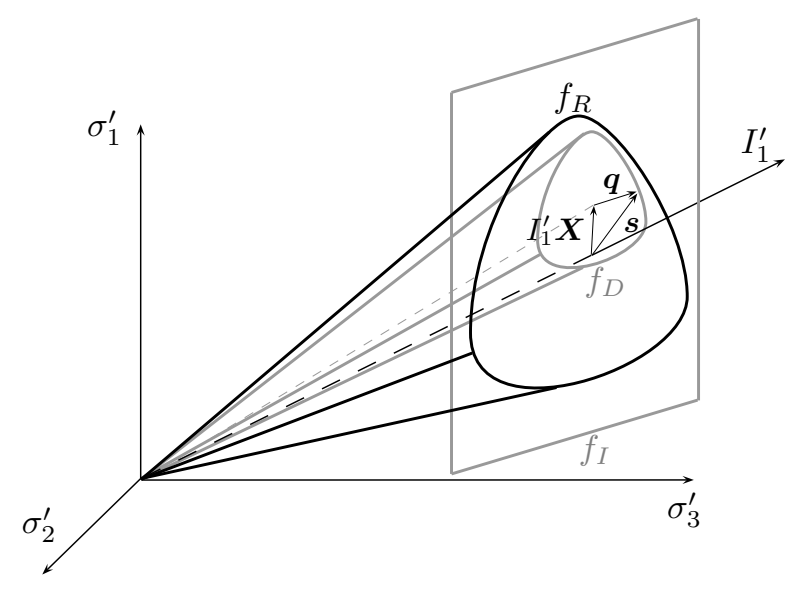

Figure 5. CJS model yield surfaces: 3-dimensional representation in effective stresses space.

Once the equivalent pore pressure is defined, the effective stress is given by the relation:

$$
\boldsymbol{\sigma}^{\prime}=\boldsymbol{\sigma}+\pi \mathbf{1}
$$

As shown in the methodology presentation, the modification of the model only concerns yield surfaces definition. The other equations remain unchanged except that the modified effective stress (as defined by Eqs. (3) and (53)) is used instead of the "classical" one. However, as it well be seen later, an additional modification will be made to improve dilatancy description.

4.2.2. Isotropic plastic mechanism Concerning the isotropic mechanism, the yield surface becomes (exactly the same modification proposed in the general formulation):

$$
f_{I}=\frac{I_{1}^{\prime}}{3}-\left(Q_{0} l_{1}(s)+l_{2}(s)\right)
$$

where $Q_{0}$ corresponds to the saturated $Q$ parameter used in the basis model.

$l_{1}(s)$ and $l_{2}(s)$ definitions are inspired from Loret and Khalili's work (see Equations (22a) and (22b)) so that transition to saturated behaviour (Eqs. 10) is satisfied:

$$
\begin{gathered}
l_{1}(s)=1+\frac{k_{1}}{s_{e}}\left(s S_{l}-s_{e}\right) \\
l_{2}(s)=k_{2}\left(s S_{l}-s_{e}\right)
\end{gathered}
$$

4.2.3. Deviatoric plastic mechanism By considering experimental observations (suction does not influence internal friction angle), the cone angle of the yield surface must remain constant while suctions varies. In order to introduce the possibility to extend (under suction increases) the elastic domain delimited by the deviatoric yield surface, a modification of the yield surface is proposed in the following way:

$$
f_{D}=q_{I I} h\left(\theta_{\boldsymbol{q}}\right)-R_{e} I_{1}^{\prime}-l_{3}(s)
$$

with $l_{3}(s)$ being defined in the same way as function $l_{2}(s)$ that is:

$$
l_{3}(s)=k_{3}\left(s S_{l}-s_{e}\right)
$$




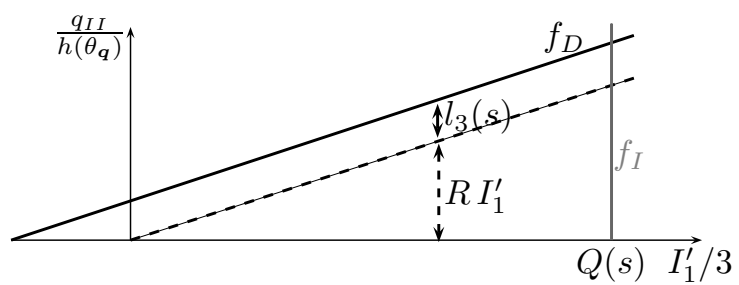

Figure 6. Extended CJS model: influence of $l_{3}(s)$ function on the deviatoric yield surface (representation in $\left(I_{1}^{\prime} / 3, q_{I I} / h\left(\theta_{\boldsymbol{q}}\right)\right)$ space at given $\theta_{\boldsymbol{q}}$ and $\left.s\right)$.

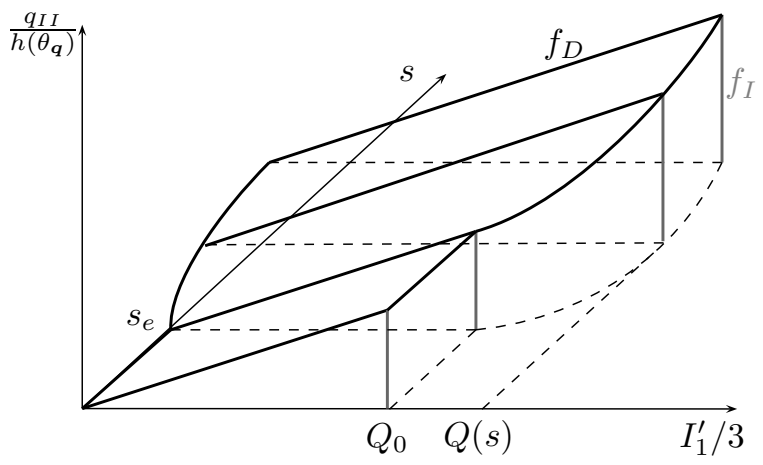

Figure 7. Extended CJS model yield surfaces: representation in $\left(I_{1}^{\prime} / 3, q_{I I} / h\left(\theta_{\boldsymbol{q}}\right), s\right)$ space at given $\theta_{\boldsymbol{q}}$.

It should be noted that this proposition leads to a translation of the yield surface in the direction of tensile stresses (see Fig. 6). Figure 7 represents both yield surfaces of the adapted model in $\left(I_{1}^{\prime} / 3, q_{I I} / h\left(\theta_{\boldsymbol{q}}\right), s\right)$ space.

Concerning the deviatoric mechanism and more particularly the definition of the characteristic surface, some experimental evidence tends to show that the dilatancy is influenced by suction (dilatancy increases when higher suctions are applied) whereas the characteristic surface itself remains independent of suction. A supplementary modification is then performed to the original model. A suction dependency of the dilatancy is introduced in the following way:

$$
\beta(s)=\beta_{0} l_{4}(s)
$$

with $l_{4}(s)$ being defined in the same way as function $l_{1}(s)$ that is:

$$
l_{4}(s)=1+\frac{k_{4}}{s_{e}}\left(s S_{l}-s_{e}\right)
$$

$\beta_{0}$ corresponds to the $\beta$ parameter of the initial CJS model and represents dilatancy at saturation. $\beta(s)$ now represents dilatancy at any given suction $s$.

In order to ensure the continuity of behaviour at the transition saturated-unsaturated states, $l_{i}$ functions are submitted to the following conditions in the saturated domain:

$$
\begin{array}{ll}
\forall s \leq s_{e}, & l_{1}(s)=l_{4}(s)=1 \\
\forall s \leq s_{e}, & l_{2}(s)=l_{3}(s)=0
\end{array}
$$


The extended model thus counts 10 "saturated" constants, 4 constants introduced by model's extension to unsaturated states ( $k_{i}$ coefficients) and 2 constants linked to the capillary pressure curve modeling $\left(s_{e}\right.$ and $\left.\alpha\right)$. Hence a total of 16 material constants have to be identified from experimental data.

\section{VALIDATION OF THE ADAPTED MODEL}

The aim of this section is to validate the adapted CJS model on various loading paths. These paths correspond to homogeneous tests for which stresses, strains and suction fields are constant within the sample. The model presented in this paper has been implemented in computations codes developed with Matlab ${ }^{\circledR}$ software.

\subsection{Triaxial compression paths}

To begin with, consider triaxial compression paths : radial total stress $\sigma_{3}$ and suction are imposed constant and the axial stress $\sigma_{1}$ is increased.

The previous model is used to fit experimental data on triaxial tests performed on unsaturated compacted silt from Jossigny, France. The experimental data used in this study comes from tests performed at constant $\sigma_{3}(=100 \mathrm{kPa})$ and at 5 different imposed suctions: $0,200,400,800$ and $1500 \mathrm{kPa}$ (see [8] for more details concerning experimental procedures).

The "mechanical" parameters have been determined using only the zero-suction curves, whereas the remaining parameters (directly related to the account for unsaturation) are obtained from the comparison of the non zero suction curves. This comparison involves both strength $\left(\epsilon_{1}, q\right)$ and volumetric $\left(\epsilon_{1}, \epsilon_{v}\right)$ curves.

Results are presented in Figure 8 and show a good agreement between experimental and numerical data. Actually, only the $0 \mathrm{kPa}$ and the $1500 \mathrm{kPa}$ suction curves have been used in this identification but it can be seen that the model predictions for the other suctions are pretty good. Material constants fitted from this study are given in Table I. It can be remarked that the $R_{e}$ parameter has been chosen close to zero thus implementing a nearly closed deviatoric yield surface (assuming no previous deviatoric hardening of the soil). It can also be seen that $l_{3}$ function has been disabled since $k_{3}=0$. In other words, the deviatoric yield surface is not affected by suction hardening in this particular case.

The model is able to reproduce increases of the overall stiffness, of the shear strength and of the dilatant behaviour appearing when higher suctions are imposed to the sample. It should be noted that the CJS model as used in this paper is not able to reproduce softening behaviour often observed after a peak in the stress-strain curves.

The CJS model results obtained during triaxial test simulations (see Figure 8) are compared to results using the Barcelona Basic Model(BBM). This comparison is plotted in Figure 9. Material parameters are summarize in Table II. This comparison shows the good abilities of both models to simulate the strength increase when the material is under partial saturation. The proposed model however shows its advantages when dealing with complex volumetric behavior. Indeed, it is able to describe dilatancy occurrence after a contractant behavior and may render for suction dependent dilatancy which is not the case with BBM. 

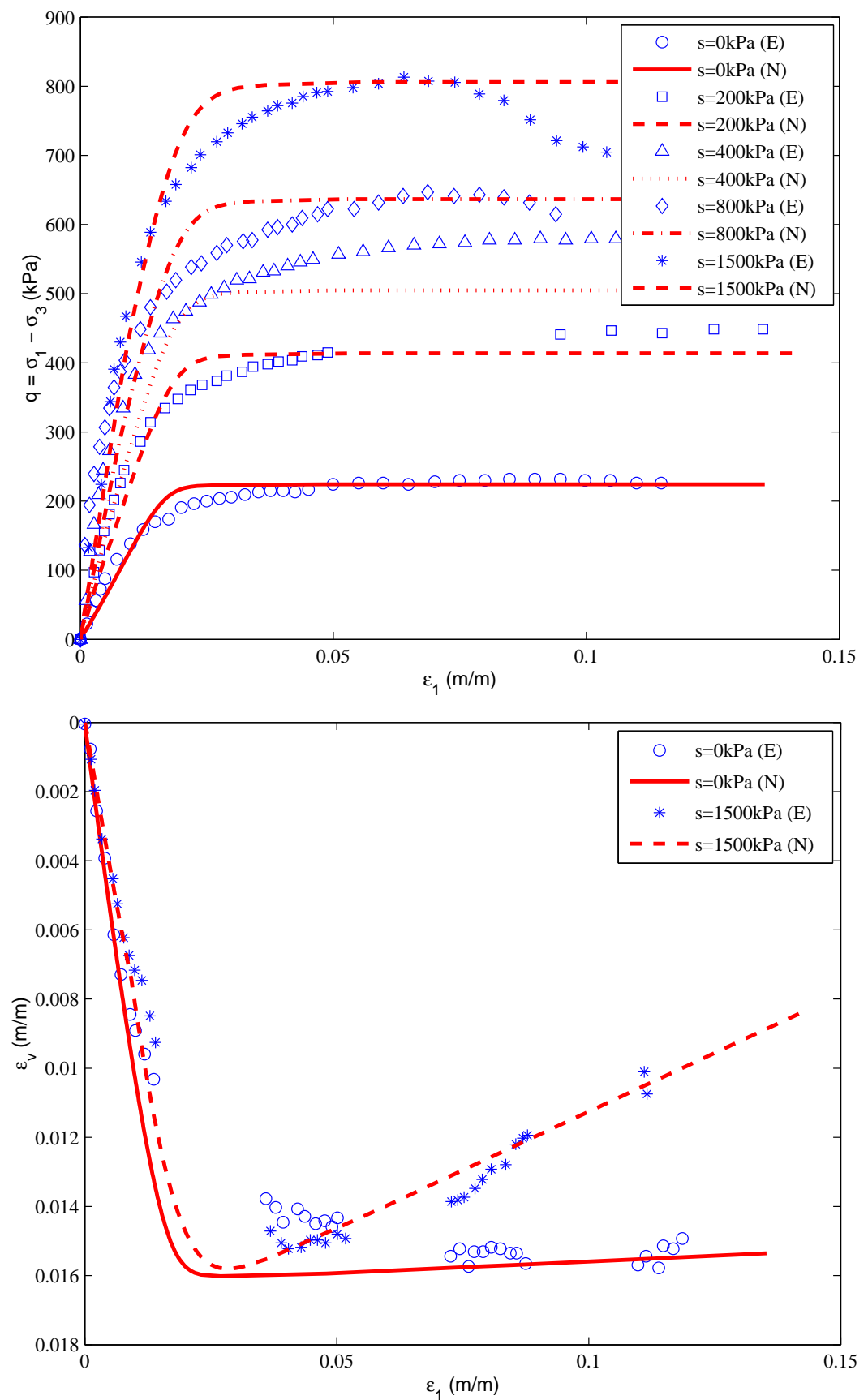

Figure 8. Triaxial compression tests at $\sigma_{3}=100 \mathrm{kPa}$ : experimental (E) data from [8] and numerical (N) simulations with adapted CJS model. Stress deviator vs axial strain (above) and volumetric strain vs axial strain (below). 

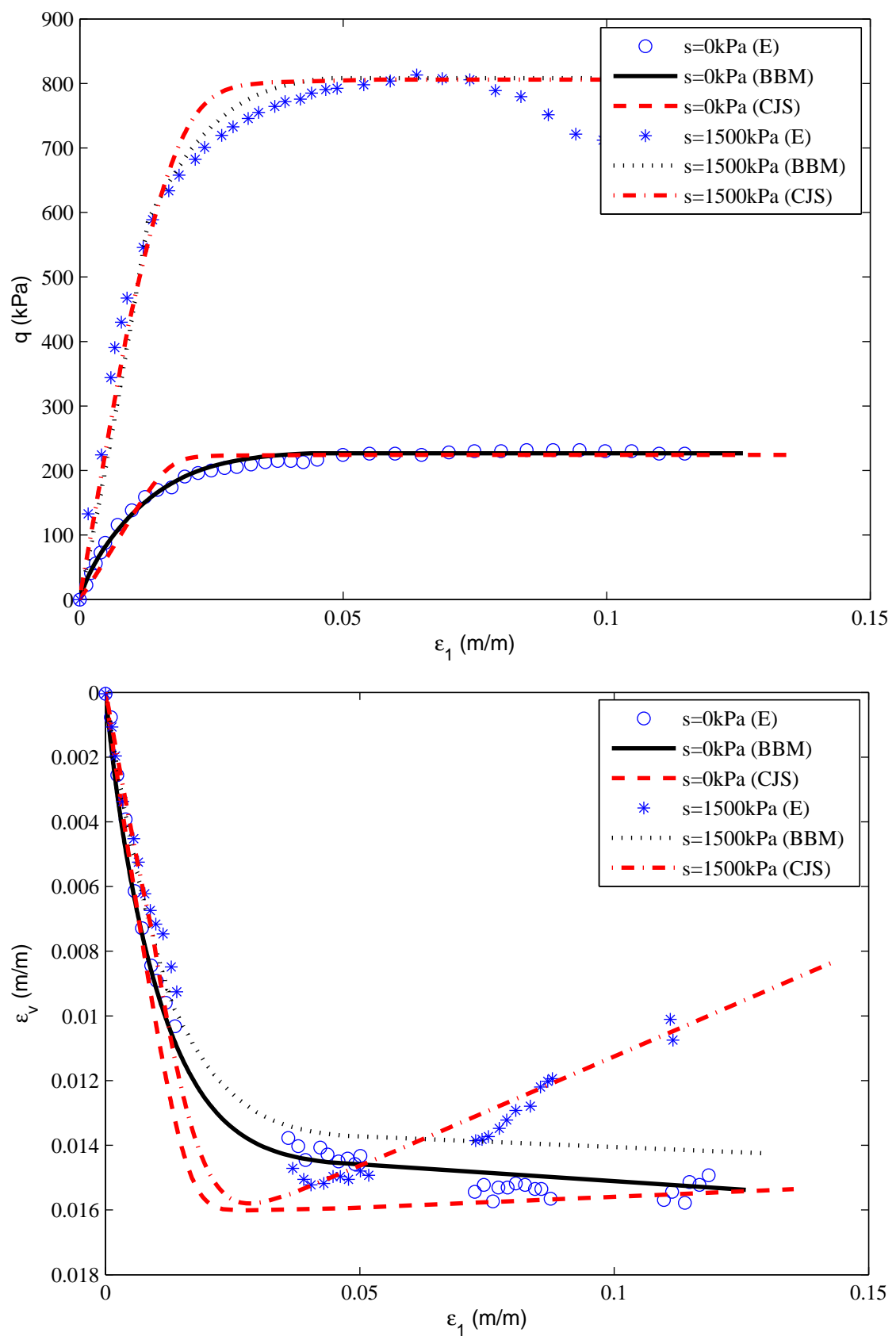

Figure 9. Triaxial compression tests at $\sigma_{3}=100 \mathrm{kPa}$ : comparison between CJS (CJS) model adapted to unsaturated soils and Barcelona Basic Model (BBM), experimental (E) data from [8]. Stress deviator vs axial strain (above) and volumetric strain vs axial strain (below). 


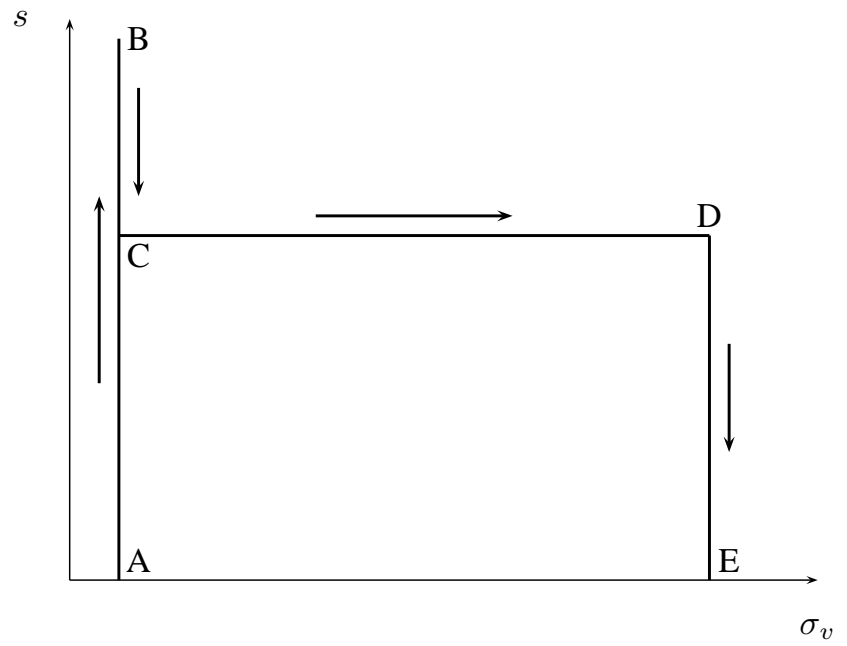

Figure 10. Stress path followed during the collapse test under œdometric conditions (in vertical stress/suction plane).

\subsection{Edometric compression paths}

A collapse test is now performed under œdometric conditions (radial displacements are prevented) and confronted to experimental data on Jossigny silt obtained by Abou-Bekr in [1]. The followed stress path is presented in Figure 10. Results are presented in Figure 11 and demonstrate the ability of the proposed model to simulate collapse phenomenon.

Materials constants have mainly been determined in order to fit the two constant vertical stress parts (from A to $\mathrm{C}$ and from D to $\mathrm{E}$ (collapse) on Figures 10 and 11) thus explaining the discrepancies between experimental and simulated data during the vertical stress increase (from $\mathrm{C}$ to $\mathrm{D}$ ). These constants are summarized in Table I.

A qualitative response of the model to œdometric compressions is then given: samples are submitted to increasing vertical stress whereas radial displacements are prevented and suction is imposed constant. The initial state correspond to an initial void ratio equal to 0.7 at zero suction and is taken as a reference for all samples. These latter are dried to each imposed suction under isotropic conditions (constant isotropic total stress) before being applied an odometric compression (which explains the dispersed initial void ratios) in Figure 12.

A higher compressibility can be observed for the zero suction test. It can also be pointed out that preconsolidation pressure increases when higher suctions are imposed. These results correspond to usual observations of unsaturated soils behaviour.

\subsection{Isotropic compression paths}

Because the previous collapse amplitude was small and in order to illustrate qualitatively the real capacity of the proposed model, we simulate an other wetting test in the triaxial apparatus used in isotropic conditions. Material constants fitted from triaxial compressions in the previous section are used in this study.

The stress path followed during this test is presented in Figure 13 (isotropic compressions under 


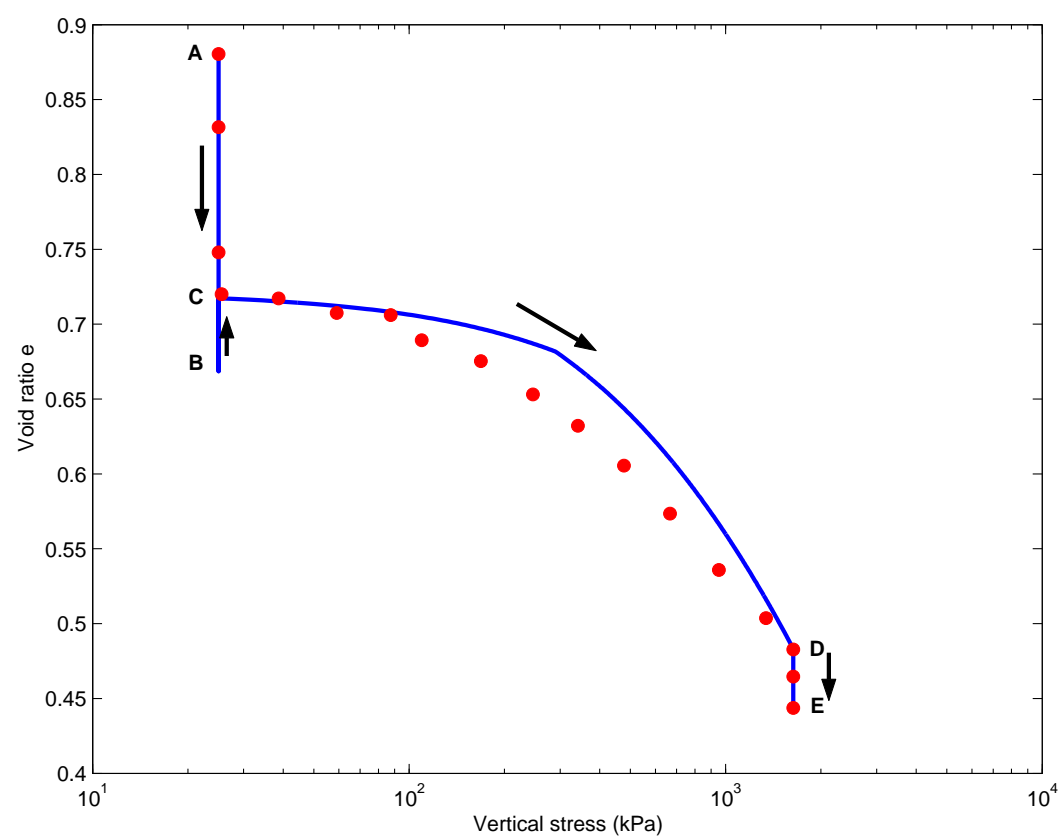

Figure 11. Collapse test under œdometric conditions (experimental data from [1]):void ratio vs vertical stress.
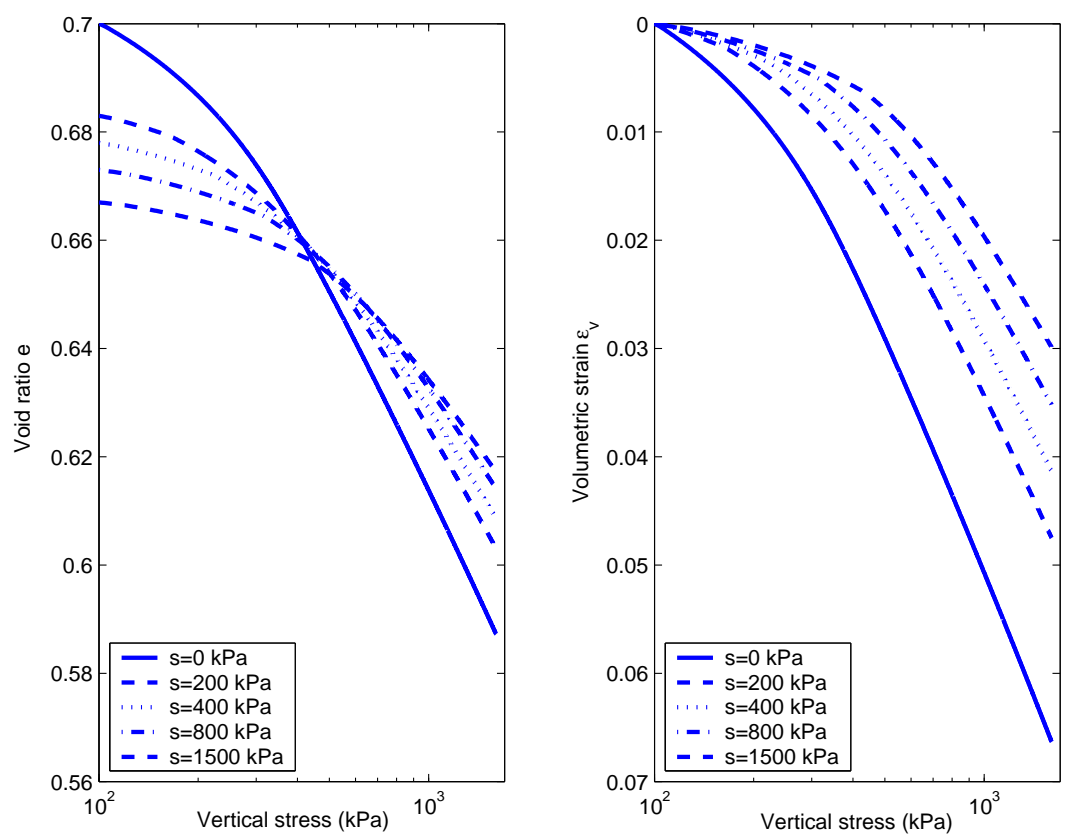

Figure 12. Edometric compressions at imposed suction: void ratio vs vertical stress (left) and volumetric strain vs vertical stress (right). 


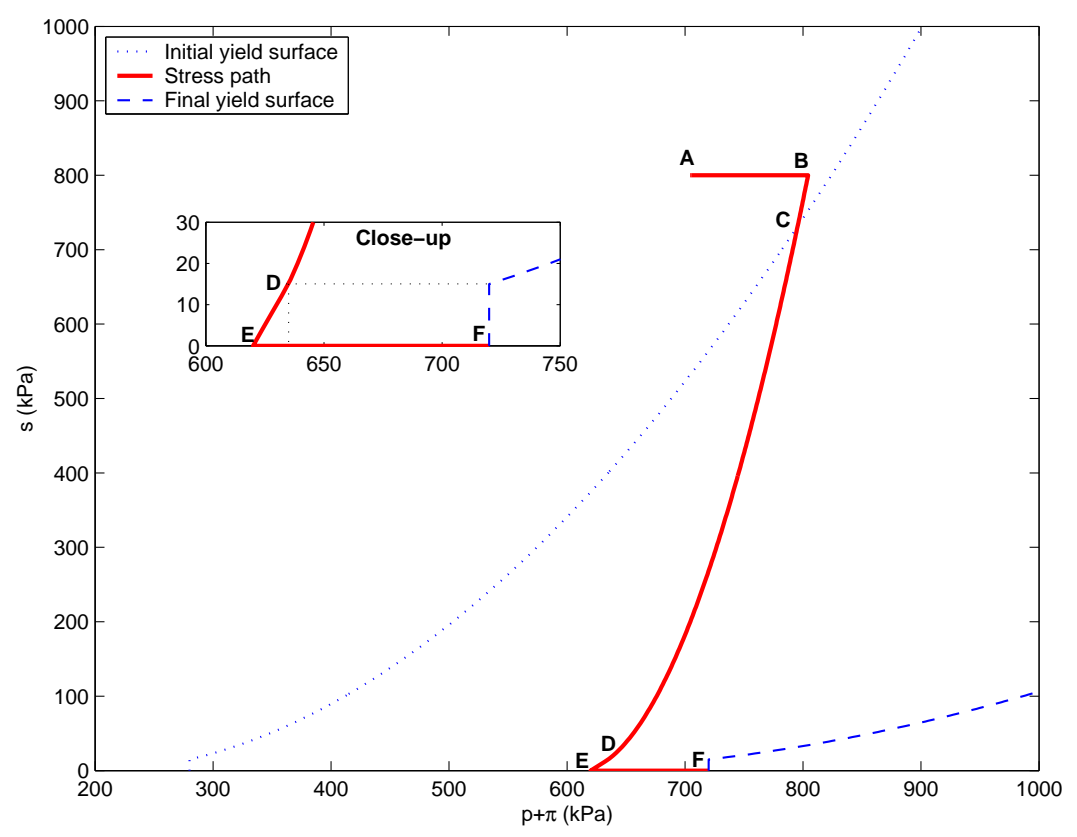

Figure 13. Stress path in $\left(p^{\prime}, s\right)$ plane followed by the sample during the wetting test in triaxial apparatus.

constant imposed suctions are carried out on the sample before and after the wetting test: between points $\mathrm{A}$ and $\mathrm{B}$ under a $800 \mathrm{kPa}$ suction and between points $\mathrm{E}$ and $\mathrm{F}$ under a null suction). Concerning the wetting test itself (between points B and E), a mean total stress of $p=620 \mathrm{kPa}$ is imposed and suction is dropped down from 800 to $0 \mathrm{kPa}$.

Results are presented in Figures 14 and 15. Between points A and B, isotropic compression is carried out in the elastic domain whereas between points $\mathrm{E}$ and F, plastic strains are observed when a certain stress is reached (point Fo in Figure 15).

Between points $\mathrm{B}$ and $\mathrm{C}$, an elastic behaviour is observed (swelling under wetting) until the stress state representative point reaches the isotropic yield surface. At point $\mathrm{C}$, plastic contractancy (higher than elastic dilatancy) occurs so that an apparent contractant behaviour appears. At point D, suction becomes lower than air entry suction and the behaviour turns elastic again thus showing a swelling part.

The model is now confronted to isotropic compression paths at constant suctions. Material constants fitted from triaxial compressions are used again. Experimental data come from tests on Jossigny silt presented by Cui \& Delage in [9].

The simulation results (Fig. 16) are qualitatively good and show again the model abilities to reproduce usual aspects of unsaturated soils behaviour under various loading paths. From a quantitative point of view, results are suitable in general and even good for certains suctions like $s=200 \mathrm{kPa}$ and $s=400 \mathrm{kPa}$ during the loading phase. The discrepancies appearing for $s=800 \mathrm{kPa}$ and $s=1500 \mathrm{kPa}$ can a priori be explained by an unsatisfactory simulation of the soil water characteristic curve (ie $S_{l}(s)$ function). 


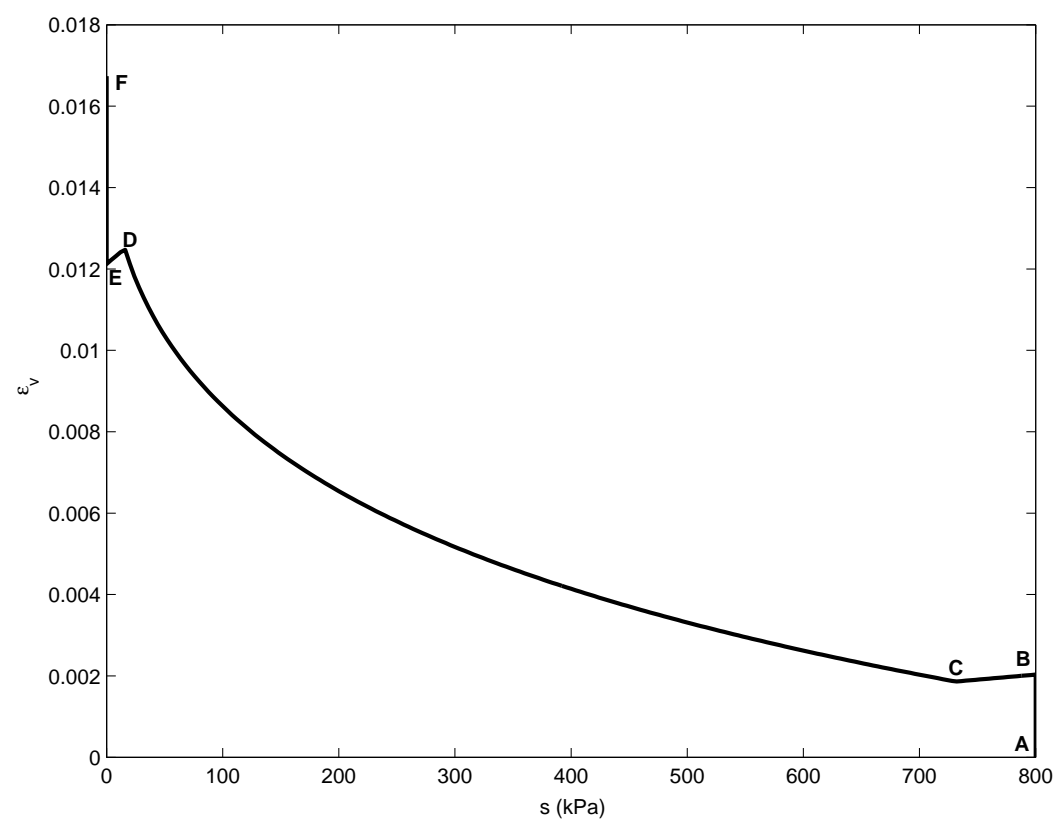

Figure 14. Wetting test under $620 \mathrm{kPa}$ isotropic stress: volumetric strains vs suction.

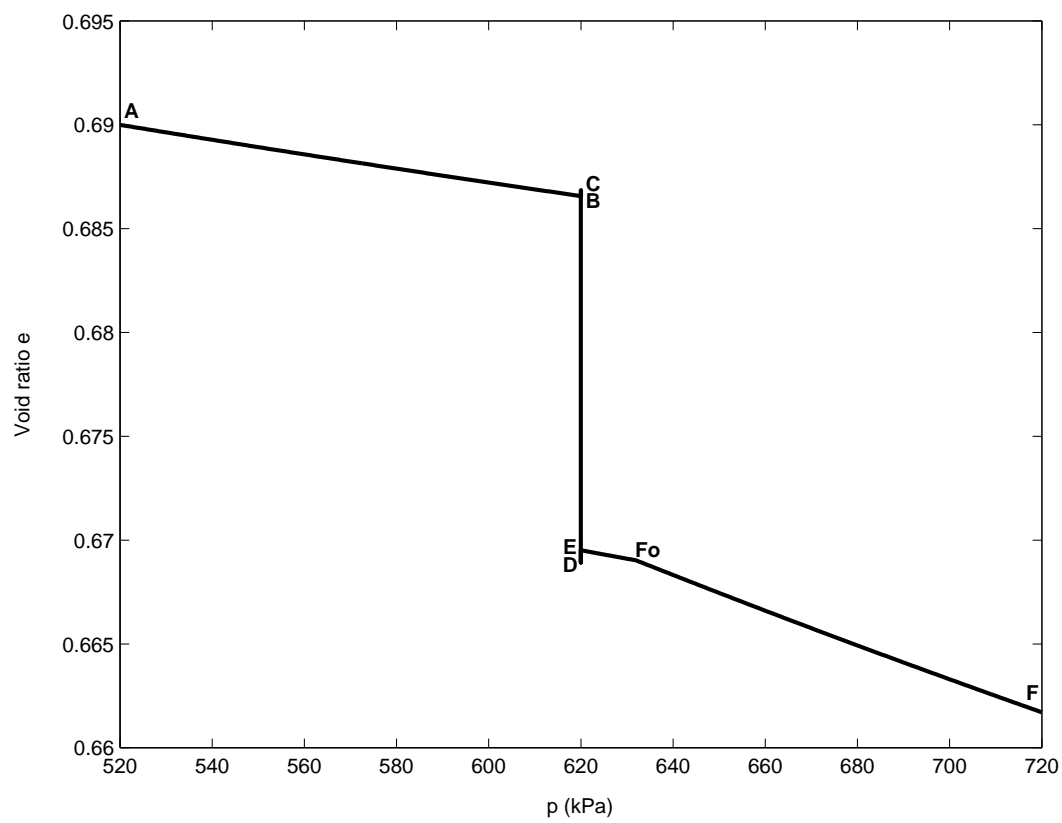

Figure 15. Wetting test under $620 \mathrm{kPa}$ isotropic stress: void ratio vs total stress. 


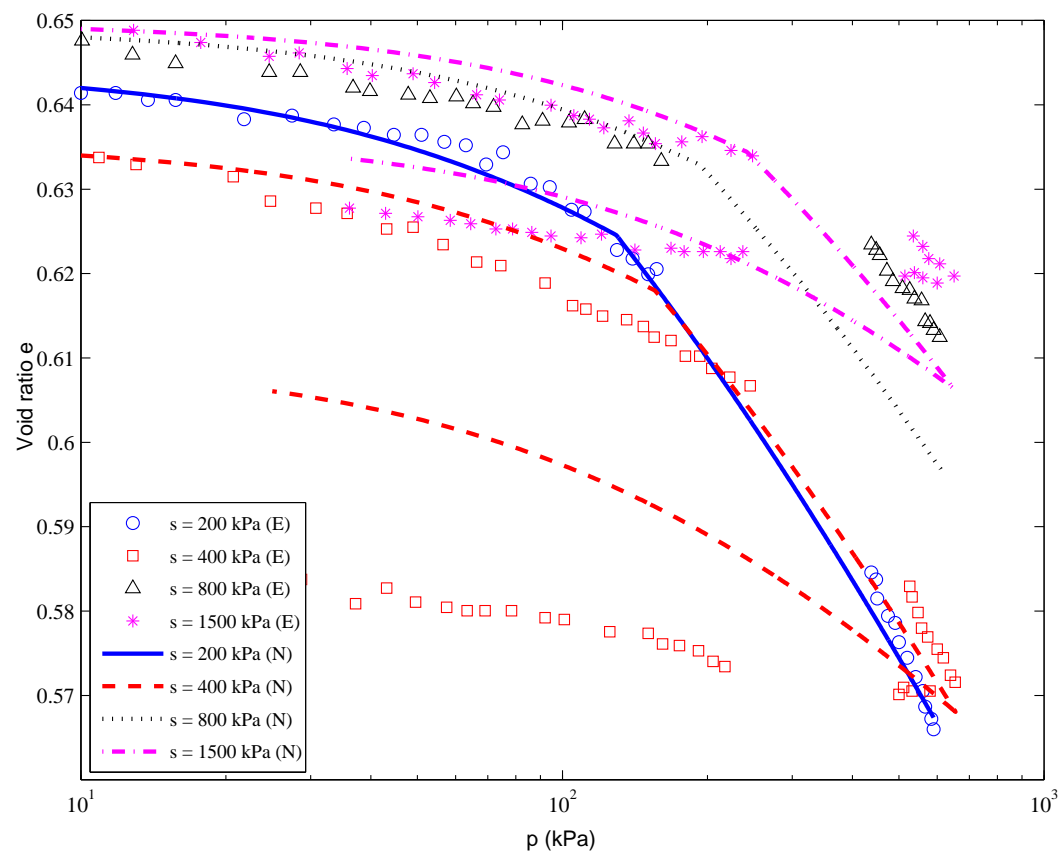

Figure 16. Isotropic compressions at imposed suction: experimental (E) data from [9] and numerical (N) simulations with adapted CJS model. Void ratio vs total mean stress.

Table I. Material constants fitted from experimental data.

\begin{tabular}{cccc}
\hline \multirow{2}{*}{ Material constant } & & \multicolumn{2}{c}{ Values fitted from } \\
& $($ Unit $)$ & Triaxial paths & Edometric paths \\
\hline$K_{0}^{e}$ & $(\mathrm{MPa})$ & 8.0 & 3.5 \\
$\nu$ & $(-)$ & 0.125 & 0.3 \\
$\gamma$ & $(-)$ & 0.8 & 0.8 \\
$R_{e}$ & $(-)$ & 0.01 & 0.01 \\
$a$ & $\left(\mathrm{kPa}^{-1}\right)$ & 0.6 & 0.6 \\
$\phi_{0}$ & $(-)$ & 3.9 & 3.9 \\
$R_{c}$ & $(-)$ & 0.26 & 0.26 \\
$\beta_{0}$ & $(-)$ & -0.2 & -0.2 \\
$K_{0}^{p}$ & $(\mathrm{MPa})$ & 6.7 & 3.0 \\
$n$ & $(-)$ & 0.9 & 0.62 \\
$k_{1}$ & $(-)$ & 0.11 & 0.05 \\
$k_{2}$ & $(-)$ & 1.9 & 1.0 \\
$k_{3}$ & $(-)$ & 0.0 & 0.0 \\
$k_{4}$ & $(-)$ & 0.9 & 0.9 \\
$s_{e}$ & $(\mathrm{kPa})$ & 15.0 & 30.0 \\
$\alpha$ & $(-)$ & 2.1 & 6.5 \\
\hline
\end{tabular}


Table II. Material constants of the Barcelona model used for comparison.

\begin{tabular}{ccc}
\hline Material constant & (Unit) & Value \\
\hline$\kappa$ & $(-)$ & 0.015 \\
$\mu$ & $(\mathrm{MPa})$ & 20 \\
$M$ & $(-)$ & 1.3 \\
$\lambda$ & $(-)$ & 0.028 \\
$\beta$ & $\left(\mathrm{kPa}^{-1}\right)$ & 0.003 \\
$r$ & $(-)$ & 0.87 \\
$k$ & $(-)$ & 0.17 \\
$p_{c}$ & $(\mathrm{kPa})$ & 0.7 \\
\hline
\end{tabular}

\section{CONCLUSIONS}

A general formulation of an isotropic behaviour model for unsaturated soils has been proposed after a review of various models recently proposed in the literature. This model is based on a two independent state variables approach, one of which being a particular effective stress. This effective stress is based on the definition of an equivalent pore pressure. It is shown that the proposed formulation actually encompasses a number of models recently published, which represent important contributions obtained via different approaches.

This model formulation can be seen as a proposition facilitating the adaptation of classical models developed within the framework of saturated soils, in order to cover unsaturated soils behaviour. This formulation has been applied to construct an original model. The basis model from which the adaptation is carried out is an advanced one : the CJS model. Its adaptation shows the abilities of the general formulation here described.

A validation of the modified CJS model has been proposed on the basis of experimental data obtained from homogeneous tests. Results are particularly interesting: thanks to the richness of the CJS model, the unsaturated version is able to describe complex volumetric responses of soils under various homogeneous loading paths.

This observation leads us to think that the suggested method is effective and allows to adapt easily existing models to unsaturated states taking advantage of the basis models strengths.

Validations of the presented model on more complex loading paths are under progress. They concern pressuremeter tests (a classic geotechnical in situ investigation method) and thus include structure effects. Results will be presented in a forthcoming paper.

\section{REFERENCES}

1. Abou-Bekr N. Modélisation du comportement mécanique et hydraulique des sols partiellement saturés. PhD thesis, École Centrale de Paris, 1995.

2. Alonso E E, Gens A, Josa A. A constitutive model for partially saturated soils. Géotechnique 1990; 40(3):405-430.

3. Bishop A W, Blight G E. Some aspects of effective stress in saturated and partly saturated soils. Géotechnique 1963; 13(3):177-197.

4. Bolzon G, Schrefler B A and Zienkiewicz O C. Elastoplastic soil constitutive laws generalized to partially saturated states. Géotechnique 1996; 46(2):279-289.

5. Cambou B, Jafari, K. Modèle de comportement des sols non cohérents. Revue Française de Géotechnique 1988; 44:43-55. 
6. Coussy O. Mechanics of porous continua. John Wiley \& Sons: New-York, 1995.

7. Coussy O, Dangla P. Approche énergétique du comportement des sols non saturés. In Mécanique des sols non saturés, Coussy O, Fleureau J-M (eds). Lavoisier: Paris, 2002.

8. Cui Y J. Etude du comportement d'un limon compacté non saturé et de sa modélisation dans un cadre élasto-plastique. $\mathrm{PhD}$ thesis, Ecole Nationale des Ponts et Chaussées, 1993.

9. Cui Y J, Delage P. Yielding and plastic behaviour of an unsaturated compacted silt. Géotechnique 1996; 46(2):291-311.

10. Dangla P. Introduction à la mécanique des milieux poreux. Cours de DEA Mécanique des Solides, des Matériaux et des Structures, Ecole doctorale MODES, Laboratoire Central des Ponts et Chaussées, 2001.

11. Dangla P. Plasticité et hystérésis. In Mécanique des sols non saturés, Coussy O, Fleureau J-M (eds). Lavoisier: Paris, 2002.

12. Elamrani K. Contributions à la validation du modèle CJS pour les matériaux granulaires. PhD thesis, Ecole Centrale de Lyon, 1992.

13. Fredlund D G, Rahardjo H. Soils mechanics for unsaturated soils. John Wiley \& Sons, Inc.: New York, 1993.

14. Gray W G and Schrefler B A. Thermodynamic approach to effective stress in partially saturated porous media. Eur. $J$. Mech. A/Solids 2001; 20: 521-538.

15. Khalili N, Khabbaz M H. A unique relationship for $\chi$ for the determination of the shear strength of unsaturated soils. Géotechnique 1998; 48(5): 681-687.

16. Kohgo Y, Nakano M, Miyazaki T. Theoretical aspects of constitutive modelling for unsaturated soils. Soils and Foundations 1993; 33(4): 49-63.

17. Kohgo Y., Nakano M., Miyazaki T. Verification of the generalized elastoplastic model for unsaturated soils. Soils and Foundations 1993 ; 33(4): 64-73

18. Laloui L, Geiser F, Vulliet L. Constitutive modelling of unsaturated soils. Revue Française de Génie Civil 2001; 5: 797-807.

19. Lewis R W, Schrefler B A. The Finite Element Method in Static and Dynamic Deformation and Consolidation of Porous Media. John Wiley \& sons: New-York, 1998.

20. Loret B, Khalili N. A three-phase model for unsaturated soils. International Journal for Numerical and Analytical Methods in Geomechanics 2000; 24(11): 893-927.

21. Loret B, Khalili N. An effective stress elastic-plastic model for unsaturated porous media. Mechanics of Materials 2002; 34(2): 97-116.

22. Maleki M, Cambou B, Dubujet Ph. Modélisation hiérarchisée du comportement des sols. Revue Française de Génie Civil 2000; 4(7-8):895-928.

23. Pereira J-M, Dubujet $\mathrm{Ph}$, Wong H. Numerical modeling of unsaturated soils in a pressuremeter test. In 16th ASCE Engineering Mechanics Conference (University of Washington, Seattle, USA), 2003.

24. Pereira J-M, Wong $\mathrm{H}$, Dubujet $\mathrm{Ph}$. A general framework for constitutive models adaptation to unsaturated states. In Deformation Characteristics of Geomaterials, IS-Lyon03 (Lyon, France), Di Benedetto H, Doanh T, Geoffroy H, Sauzéat C, (eds), Balkema, 2003; 1269-1276.

25. Sheng D, Sloan S W, Gens A, Smith D W. Finite element formulation and algorithms for unsaturated soils Part I: Theory. International Journal for Numerical and Analytical Methods in Geomechanics 2003; 27:745-765.

26. Sheng D, Sloan S W, Gens A. A constitutive model for unsaturated soils: thermomechanical and computational aspects. Computational Mechanics 2004; 33(6):453-465.

27. Terzaghi K. Theoretical soil mechanics. John Wiley \& Sons: New York, 1943.

28. Wheeler S J. Inclusion of specific water volume within an elasto-plastic model for unsaturated soil. Canadian Geotechnical Journal 1996; 33:42-57.

29. Wheeler S J, Sivakumar V. An elasto-plastic critical state framework for unsaturated soil. Géotechnique 1995; 45(1):35-53.

30. Zienkiewicz O C, Chan A H C, Schrefler B A, Shiomi T. Computational geomechanics with special reference to earthquake engineering. John Wiley \& Sons: New-York, 1999. 